\title{
Stereotactic Brainstem Biopsy: Technical Aspects with Emphasis on Role of Awake Craniotomy
}

\author{
Reddy Kanala Ramnadh ${ }^{1}$ Krishna Yerramneni Vamsi ${ }^{1}$ Thirumal Yerragunta ${ }^{1}$ \\ Kumar Vupuloori Arvind ${ }^{1}$ Varshesh Shah ${ }^{1}$
}

${ }^{1}$ Department of Neurosurgery, Nizam's Institute of Medical

Sciences, Panjagutta, Hyderabad, Telangana, India

\begin{abstract}
Address for correspondence Vamsi Krishna Yerramneni, MCh, Nizam's Institute of Medical Sciences, Punjagutta, Hyderabad 500082, Telangana,
\end{abstract} India (e-mail: vamsiky.ns@gmail.com).

Indian J Neurosurg:2020;9:80-84

\begin{abstract}
Introduction The role of frame-based stereotactic biopsy in brainstem lesions has been well established in literature. Transfrontal, transtentorial, and transcerebellar routes are used to access various targets within the brainstem. While the transfrontal approach is preferable in midbrain lesions, a transcerebellar approach via the middle cerebellar peduncle forms the shortest possible trajectory for pontine and medullary lesions.

Objective Authors to describe the technical nuances of frame-based stereotactic biopsy of lower brainstem lesions to increase the procedural safety and efficacy.

Materials and Methods Technical modifications in frame fixation were done to acheive the desired trajectory to the target. In adult cases biopsy was performed with patient awake during the procedure.

Results Total of five patients underwent biopsy with the technical modifications. Three patients were adults and two were in pediatric age group. Their age ranged from 12 to 50 years. No complications were encountered. Two of the biopsies showed demyelination and the other three turned out to be low-grade glioma, pilocytic astrocytoma, and lymphoma, respectively.

Keywords

- stereotactic biopsy

- brainstem lesions

- awake craniotomy

Conclusion Despite obvious inherent risks, the transcerebellar biopsy in semi-sitting position is a well-tolerated and effective method of obtaining a diagnostic tissue sample in brainstem lesions. We have noted that adoption of the technical modifications described in this article has aided in improving the safety and ease of the procedure.
\end{abstract}

\section{Introduction}

Brainstem lesions contribute around $15 \%$ in children and $2 \%$ in adults of total intracranial space occupying lesions. ${ }^{1}$ In children, majority of these lesions are brainstem gliomas while there is a wider heterogeneity in adults. ${ }^{2}$ In addition to glioma, the differential diagnosis of a brainstem lesion in adults includes other tumors, vasculitis, arteriovenous malformation, hematoma, infarction, infections, gliosis, and demyelinating disease. ${ }^{3,4}$ Differentiating various lesions mandates biopsy, except in cases of vascular malformations.

In the cases of diffuse intrinsic pontine gliomas, the newer studies have shown the importance of molecular biology-based treatments necessitating stereotactic biopsy. ${ }^{5-7}$ Furthermore, tissue sampling enhances the knowledge about the origin of pediatric and adult brainstem gliomas, its cellular composition, and architecture of cells where we have limited knowledge in this type of tumors. ${ }^{8-10}$

Open biopsy for brainstem lesions is not recommended owing to the extensive skull base work it requires and the damage it could cause to long fiber tracts and the nuclei.. ${ }^{11}$ The frame-based stereotactic biopsy role as the minimalistic and the less morbid procedure to the brainstem lesions has been well established in the literature. ${ }^{3,12-21}$ The present article describes the technique of stereotactic brainstem biopsy, which includes changes to be made in the frame fixation
DOI https://doi.org/

$10.1055 / \mathrm{s}-0039-3402623$

ISSN 2277-954X.
License terms

(ㅇ) (1) $\ominus \circledast$ 
alignment, trajectories to be taken, type of anesthesia, awake craniotomy, and other aspects to increase the yield of the biopsy. The authors analyzed the results of their series of brainstem biopsies as well.

\section{Materials and Methods}

Patients having symptomatic brainstem lesions with no definitive diagnosis based on imaging were considered for stereotactic biospy. Demographic and clinical data abstracted from the records include age at the time of biopsy, sex, preoperative Karnofsky performance scale, presenting symptoms, and duration of symptoms and probable differential diagnosis before surgery. Type of anesthesia, surgical trajectory taken, number of passes, operating time, and complications postsurgery, and final biopsy reports were collected. Predicted differential diagnoses were determined from the review of preoperative neuroradiology reports and neurosurgical records. Lesion location was recorded after review of the preoperative magnetic resonance imaging (MRI) scans and computed tomographic images. Formal pathology reports were reviewed to establish frozen section and final pathological diagnoses. Definitive treatment given following biopsy were noted.

\section{Technique}

Stereotactic biopsy was done using Cosman-Roberts-Wells (CRW) frame. All biopsies in adult patients were done under local anesthesia (LA). General anesthesia (GA) was preferred in pediatric patients. Some technical modifications were done in frame fixation to target the brainstem. Some of the technical modifications required to accomplish the brainstem biopsy include (1) fixation of the frame as low as possible, (2) Frame is fixed with shift from the midline toward the side of the lesion. Besides that slight rotation in an axial plane toward the side of the lesion is given to avoid the posterior vertical bar coming in the line of trajectory. (3) Target coordinates to be based on T2W MRI axial images obtained after the frame placement; (4) for pons and the medulla, the trajectory was chosen through the cerebellum and subsequently, the cerebellar peduncles. Trajectory is chosen in such a way to avoid the cranial nerve nuclei and the tracts. (5) For the midbrain, the trajectory is taken through the cerebral hemisphere. In cases of trans temporal trajectory to the midbrain, the arc ring system can be fixed in such a way that the arc will be along the sagital axis of the skull with rings in the anterior and posterior aspects. Such alignment ensures a perpendicular trajectory through the temporal lobe to the midbrain ( $\mathbf{- F i g}$. 3F). In such cases, the coordinates given by the software as anterior posterior $(\mathrm{Y})$ become lateral (X) and vice versa. (6) Semi-sitting position is preferred for the biopsy. (7) The arc ring system is fixed reverse on the phantom base to have cylinder downward to gain entry into the cerebellum below the transverse sinus. (8) The two samples apart from the sample at the target were taken at a distance of 3-mm superficial and deep instead of $10 \mathrm{~mm}$.
The procedure starts by fixing the stereotactic frame under LA at pin site and sedation. In children the frame fixation is done under GA. MRI T2 sequences are done as the T2 sequences show the fiducials better to be recognized by the software. Any additional sequences are done if it is required to see the lesion better. Planning is done on the Radionics software by the Integra or frame link software by Medtronic. In adults, the entire procedure is done under LA while in pediatric patients the procedure is performed under GA. After the skin incision and burr hole or twist drill placement was done, a small hole is made in the dura, sufficient enough to pass the biopsy needle. A 5-mm Nashold biopsy needle is preferable instead of a 9-mm needle. In adults, sedation was given if the passage of the biopsy needle through the spinal tract of the trigeminal nerve caused tingling over the face. Before removing the head frame, immediate check computed tomography (CT) was done in all cases to see the specs of air in the target as well as to rule out hematomas.

\section{Case Details}

Five patients underwent stereotactic biopsy applying the technical modifications proposed by the authors ( $\mathbf{- T a b l e} \mathbf{1}$ ). First two cases have been described in detail with images.

\section{Case 1}

A 21-year-old-female patient presented with left upper limb paresthesia for 5 day. She had been evaluated for this complaint and found to have right medulla and cervicomedullary junction lesion. MRI T2-weighted images (T2WI) showed hyper intense lesion in lower part of the medulla which was nonenhancing on contrast images. Radiological diagnosis was demyelination versus glioma. Our neurology team evaluated her and referred her to us for biopsy. As described above, we applied frame and biopsy was done in a semi-sitting position and awake status. Transcerebellar biopsy was done through the inferior cerebellar peduncle. Once the needle was advanced to the level of the spinal trigeminal tract at the border of the pons and middle cerebellar peduncle, patient had a complaint of severe facial pain, for which we had given a bolus of propofol. The biopsy confirmed it as demyelination. Patient was discharged in stable condition without neurological deficits on day 1 postoperatively ( - Fig. 1 ).

\section{Case 2}

A 12-year-old male child presented with complaints of headache. MRI showing left middle cerebellar peduncle and brainstem junction hyperintensity in T2WI which was not enhanced on contrast images with differential diagnosis of demyelination, glioma, and medulloblastoma ( - Fig. 2). According to the anterior-posterior, lateral, and vertical coordinates, the arc ring system was fixed to the phantom base. Burr hole was made on the left side and biopsy taken through middle cerebellar peduncle. Check CT was done immediately before removing frame. Biopsy turned out to be a pilocytic astrocytoma in this patient (-Figs. 2 and $\mathbf{3}$ ). 

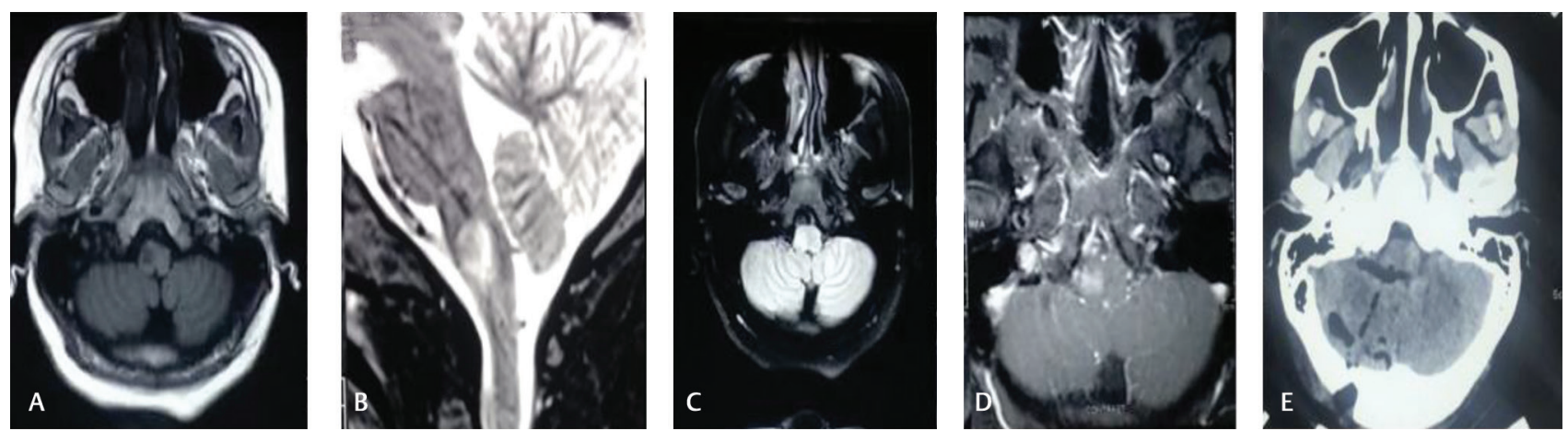

Fig. 1 (A) Image showing that bars should be fixed at the lowest point on the head frame. Image showing semi-sitting position and head frame fixation on the patient as low as possible and shifted toward the lesion side. (B) Cylinder touching the posterior X-axis which will hamper the lowest burr hole placement if frame not fixed as low as possible on the head. (C) MRI T2WI showing trajectory passing through MCP. (D) Image showing the final burr hole placement and biopsy needle passing through the cylinder. (E) Arc ring system fixed to the phantom base along the sagital axis of the skull with rings in the anterior and posterior aspect. MRI, magnetic resonance imaging; T STB, stereotactic biopsy; 2WI, T2-weighted images.

Table 1 Demographics, preoperative radiological location of lesion, type of anesthesia, biopsy trajectory, postoperative complications, and final biopsy report of five patients

\begin{tabular}{|l|l|l|l|l|l|l|l|}
\hline No. & Age/Sex & $\begin{array}{l}\text { KPS } \\
\text { score }\end{array}$ & $\begin{array}{l}\text { Preoperative } \\
\text { MRI } \\
\text { site of lesion }\end{array}$ & Anesthesia & Trajectory & Complications & Biopsy \\
\hline 1. & 21 & $>70$ & Medulla & LA & $\begin{array}{l}\text { Inferior } \\
\text { cerebellar } \\
\text { peduncle }\end{array}$ & $\begin{array}{l}\text { Temporary LtUL } \\
\text { paresthesia }\end{array}$ & Demyelination \\
\hline 2. & 12 & $>70$ & Pons & GA & $\begin{array}{l}\text { Middle } \\
\text { cerebellar } \\
\text { peduncle }\end{array}$ & Nil & Pilocytic astrocytoma \\
\hline 3. & 50 & $<70$ & $\begin{array}{l}\text { Peduncle and } \\
\text { vermis } \\
\text { cerebellar } \\
\text { peduncle }\end{array}$ & LA & $\begin{array}{l}\text { Inferior } \\
\text { cerebellar } \\
\text { peduncle }\end{array}$ & Nil & Lymphoma \\
\hline 4. & 10 & $>70$ & Medulla & GA & $\begin{array}{l}\text { Inferior } \\
\text { cerebellar } \\
\text { peduncle }\end{array}$ & Nil & Dew-grade glioma \\
\hline 5. & 18 & $>70$ & $\begin{array}{l}\text { Inferior cerebellar } \\
\text { peduncle }\end{array}$ & LA & & Dil & \\
\hline
\end{tabular}

Abbreviations: GA, general anesthesia; LA, local anesthesia; MRI, magnetic resonance imaging.
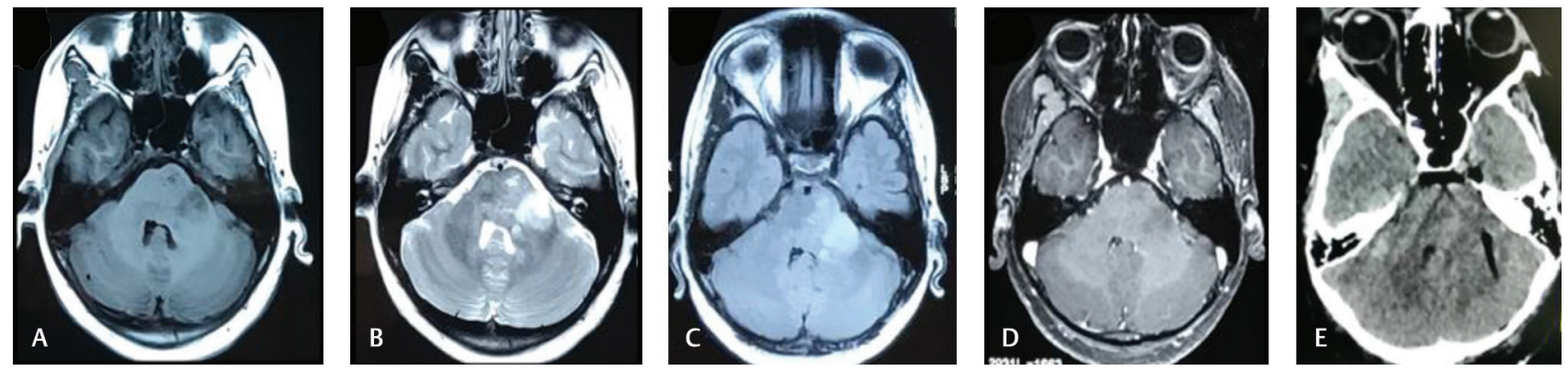

Fig. 2 Images show (A) T1 hypointense, (B) T2 hyperintense sagittal sections, (C) FLAIR hyperintensity with surrounding edema, (D) contrast mildly enhancing lesion in the left medulla. (E) Postoperative CT scan shows Burr hole site and air foci in the trajectory and target size. FLAIR, fluid attenuated inversion recovery.

\section{Discussion}

Stereotactic brainstem biopsy is an essential method for diagnosis of most brainstem lesions, considering the fact that operating on the brainstem involves high morbidity and mortality. Molecular characterization of tumors like in pediatric diffuse brainstem gliomas, individualized treatment concepts mandate STB (22-24). ${ }^{22-24}$ Even in adults, diversity of brainstem 

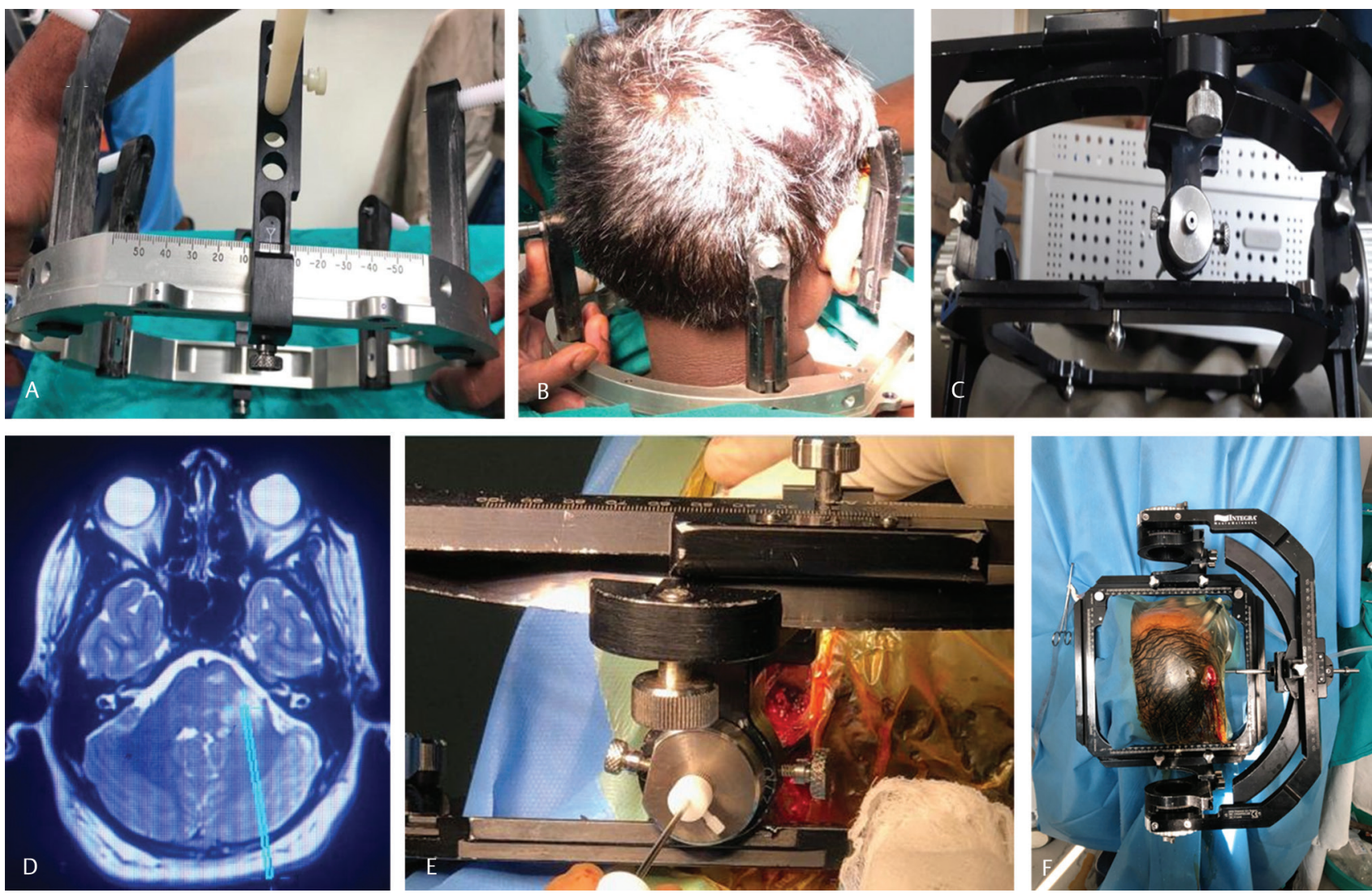

Fig. 3 (A) T1 hypointense, (B) T2 hyperintense, (C) FLAIR hyperintensity with surrounding edema, (D) contrast nonenhancing lesion in the left middle cerebellar peduncle and pons. (E) Postoperative scan showing air foci in the trajectory and target site. (F) FLAIR, fluid attenuated inversion recovery.

lesions mandates tissue sampling. Frame-based stereotactic biopsy is a more precise way of approaching the lesion with minimal damage to the vital tracts and nuclei in the brainstem. The authors described the technical modifications required for the routine frame fixation to achieve the desired trajectory.

In adults, our opinion to do an awake transcerebellar biopsy using a stereotactic head frame in a semi-sitting position is a safe and effective technique compared to an open transfrontal approach. In pediatric age group, we prefer entire procedure including frame fixation under GA. The modifications we made to the standard surgical technique for transcerebellar stereotactic biopsies have distinct advantages. An awake procedure in adults also allows for patients to be monitored intraoperatively for neurological deficits.

After making burr hole we made a small opening in the dura which is sufficient enough to pass biopsy side cutter needle. By this we can reduce the risk of air embolus, which is one of the major concerns when the patient is operated in the semi-sitting position. Though prone or lateral positions have been described in the literature, ${ }^{17,18,25}$ these positions increase the complexity of the operative step, as the Mayfield attachments are in a posterior position on the CRWbased ring.

In the five cases, the authors had no complications, but the study has limitation of small numbers. Samadani et al was reported diagnostic yield of $94 \%$ after the first biopsy and $96 \%$ after the second biopsy. ${ }^{26}$ Few studies have reported that transient and permanent neurological deficits were 4 and $1 \%$, respectively, while $0.3 \%$ mortality was reported. ${ }^{2}$

\section{Conclusion}

Molecular biology and diversity of pathology mandate tissue sampling in brainstem lesions. Although reported complications of stereotactic biopsy are rare, they could be devastating to the patient's life. Despite these inherent risks, successful brainstem biopsies can individualize treatment options to the patient and provides prognostic information as well. Framebased stereotactic transcerebellar biopsy of the brainstem is a safe and effective method. The technical modifications of frame fixation authors proposed may increase the ease of getting the transcerebellar trajectory to the brainstem. Awake STB of brainstem may increase the safety of the procedure.

\section{Conflict of Interest}

None declared.

\section{References}

1 Pereira EA, Jegan T, Green AL, Aziz TZ. Awake stereotactic brainstem biopsy via a contralateral, transfrontal, transventricular approach. Br J Neurosurg 2008;22(4):599-601

2 Samadani U, Stein S, Moonis G, Sonnad SS, Bonura P, Judy KD. Stereotactic biopsy of brain stem masses: decision analysis and literature review. Surg Neurol 2006;66(5):484-490, discussion 491 
3 Abernathey CD, Camacho A, Kelly PJ. Stereotaxic suboccipital transcerebellar biopsy of pontine mass lesions. J Neurosurg 1989;70(2):195-200

4 Epstein F, McCleary EL. Intrinsic brain-stem tumors of childhood: surgical indications. J Neurosurg 1986;64(1):11-15

5 Rajshekhar V, Moorthy RK. Status of stereotactic biopsy in children with brain stem masses: insights from a series of 106 patients. Stereotact Funct Neurosurg 2010;88(6):360-366

6 Wilkinson R, Harris J. Moral and legal reasons for altruism in the case of brainstem biopsy in diffuse glioma. Br J Neurosurg 2008;22(5):617-618

7 Brodbelt A. Commentary on diffuse brain stem glioma in children. Br J Neurosurg 2008;22(5):625

8 Hargrave D, Bartels U, Bouffet E. Diffuse brainstem glioma in children: critical review of clinical trials. Lancet Oncol 2006;7(3):241-248

9 Nishio S, Fukui M, Tateishi J. Brain stem gliomas: a clinicopathological analysis of 23 histologically proven cases. J Neurooncol 1988;6(3):245-250

10 Nishio S, Takeshita I, Fujii K, Fukui M. Brain stem glioma: the role of a biopsy. Br J Neurosurg 1991;5(3):265-273

11 Gleason CA, Wise BL, Feinstein B. Stereotactic localization (with computerized tomographic scanning), biopsy, and radiofrequency treatment of deep brain lesions. Neurosurgery 1978;2(3):217-222

12 Amundson EW, McGirt MJ, Olivi A. A contralateral, transfrontal, extraventricular approach to stereotactic brainstem biopsy procedures. Technical note. J Neurosurg 2005;102(3):565-570

13 Boviatsis EJ, Kouyialis AT, Stranjalis G, Korfias S, Sakas DE. CT-guided stereotactic biopsies of brain stem lesions: personal experience and literature review. Neurol Sci 2003;24(3):97-102

14 Coffey RJ, Lunsford LD. Stereotactic surgery for mass lesions of the midbrain and pons. Neurosurgery 1985;17(1):12-18

15 Giunta F, Marini G, Grasso G, Zorzi F. Brain stem expansive lesions: stereotactic biopsy for a better therapeutic approach. Acta Neurochir Suppl (Wien) 1988;42:182-186
16 Gonçalves-Ferreira AJ, Herculano-Carvalho M, Pimentel J. Stereotactic biopsies of focal brainstem lesions. Surg Neurol 2003;60(4):311-320, discussion 320

17 Guthrie BL, Steinberg GK, Adler JR. Posterior fossa stereotaxic biopsy using the Brown-Roberts-Wells stereotaxic system. Technical note. J Neurosurg 1989;70(4):649-652

18 Kondziolka D, Lunsford LD. Results and expectations with image-integrated brainstem stereotactic biopsy. Surg Neurol 1995;43(6):558-562

19 Kratimenos GP, Thomas DG. The role of image-directed biopsy in the diagnosis and management of brainstem lesions. $\mathrm{Br} \mathrm{J}$ Neurosurg 1993;7(2):155-164

20 Rajshekhar V, Chandy MJ. Computerized tomography-guided stereotactic surgery for brainstem masses: a risk-benefit analysis in 71 patients. J Neurosurg 1995;82(6):976-981

21 Steck J, Friedman WA. Stereotactic biopsy of brainstem mass lesions. Surg Neurol 1995;43(6):563-567, discussion 567-568

22 Buczkowicz P, Hoeman C, Rakopoulos P, et al. Genomic analysis of diffuse intrinsic pontine gliomas identifies three molecular subgroups and recurrent activating ACVR1 mutations. Nat Genet 2014;46(5):451-456

23 Grasso CS, Tang Y, Truffaux N, et al. Functionally defined therapeutic targets in diffuse intrinsic pontine glioma. Nat Med 2015;21(6):555-559

24 Schroeder KM, Hoeman CM, Becher OJ. Children are not just little adults: recent advances in understanding of diffuse intrinsic pontine glioma biology. Pediatr Res 2014;75(1-2): 205-209

25 Spiegelmann R, Friedman WA. Stereotactic suboccipital transcerebellar biopsy under local anesthesia using the Cosman-Roberts-Wells frame. Technical note. J Neurosurg 1991;75(3):486-488

26 Samadani U, Judy KD. Stereotactic brainstem biopsy is indicated for the diagnosis of a vast array of brainstem pathology. Stereotact Funct Neurosurg 2003;81(1-4):5-9 